\title{
Tratamento Contábil no Mercosul e na Comunidade Andina: Um Estudo sobre os Investimentos em Empresas Coligadas e Controladas
}

\begin{abstract}
João Luis Peruchena Thomaz Mestrado em Ciências Contábeis pela Universidade do Vale do Rio dos Sinos UNISINOS Avenida Unisinos, 950. Bairro Cristo Rei. São Leopoldo/RS. CEP: 93022-000 E-mail: prof.peruchena@gmail.com
\end{abstract}

Clóvis Antônio Kronbauer Doutorado em Contabilidad y Auditoría pela Universidad de Sevilla - US/Espanha. Professor da Universidade do Vale do Rio dos Sinos - UNISINOS Avenida Unisinos, 950. Bairro Cristo Rei. São Leopoldo/RS. CEP: 93022-000 E-mail: Clovisk@unisinos.br

Diego Saldo Alves Mestrado em Ciências Contábeis pela Universidade do Vale do Rio dos Sinos UNISINOS Professor da Faculdade Dom Alberto - FDA Rua Ramiro Barcelos, 892. Centro/RS. CEP: 96810-054

E-mail: diego.acta@gmail.com

Adriana Kurtz Pasini Mestrado em Ciências Contábeis pela Universidade do Vale do Rio dos Sinos UNISINOS Professora da Faculdade Ideau de Passo Fundo Rua Rui Barbosa. Bairro Petrópolis. Passo Fundo/RS. CEP: 99050120 E-mail:adriana_pasini@yahoo.com.br

Debora Skibinksi Assumpção Mestrado em Ciências Contábeis pela Universidade do Vale do Rio dos Sinos UNISINOS Professora da Faculdade Porto Alegrense de Ciências Contábeis e Administração -

FAPA Rua Manoel Elias, 2001. Porto Alegre/RS. CEP: 91240-261 E-mail: deboraassumpcao@terra.com.br

\section{RESUMO}

O objetivo do presente estudo é investigar o nível de convergência às normas internacionais de contabilidade quanto ao tratamento contábil dispensado aos investimentos em coligadas e controladas de empresas industriais sediadas nos países do Mercosul e da Comunidade Andina. Analisou-se a mensuração e a evidenciação dos 
Tratamento Contábil no Mercosul e na Comunidade Andina: Um Estudo sobre os Investimentos em Empresas Coligadas e Controladas João Luis Peruchena Thomaz, Clóvis Antônio Kronbauer, Diego Saldo Alves, Adriana Kurtz Pasini,

itens que compõem o Ativo em uma amostra de trinta empresas industriais destes dois blocos econômicos. A amostra foi escolhida por critério de intencionalidade e acessibilidade, sendo que os dados foram obtidos nas páginas eletrônicas dos órgãos nacionais encarregados de controlar e fiscalizar os mercados de capitais em cada país. Com os dados coletados foram elaborados quadros-resumo relativos à mensuração e à evidenciação desses ativos, os quais foram submetidos à análise descritiva. Em geral, constatou-se que no ano de 2012 as práticas adotadas estavam convergentes com o que preconiza a IAS 28 nos diferentes países. Observou-se a convergência quase total às normas internacionais emitidas pelo IASB; na Bolívia seguem vigentes as normas locais emitidas pelo CAUB, e na falta de pronunciamento são utilizadas as normas do IASB; no caso do Chile está prevista a convergência normativa para o ano de 2013; já na Colômbia para 2015. Assim, é possível afirmar que há ainda um caminho a percorrer para que nos países da Comunidade Andina as práticas contábeis relativas aos investimentos em coligadas e controladas estejam completamente harmonizadas, convergindo ao padrão contábil internacionalmente aceito.

Palavras-chave: Mensuração e Evidenciação. Investimentos em Coligadas e Controladas. Convergência Contábil. Mercosul. Comunidade Andina.

\section{Accounting Treatment in Mercosur and Andean Community: A Study on Investments in Associates and Subsidiaries Enterprises}

\section{ABSTRACT}

The objective of the study is to investigate the level of convergence with international accounting standards in relation to the accounting treatment of investments in associated companies and industrial firms in the countries of MERCOSUR and the Andean Community. We analyzed the measurement and disclosure of the items that make up the Active on a sample of thirty industrial companies of these two economic blocs. The sample was chosen by criteria of intentionality and accessibility, and the data obtained from the electronic pages of the national bodies responsible for controlling and supervising capital markets in each country. The data collected were subjected to descriptive analysis for preparation of abstracts, tables relating to the measurement and disclosure of these assets. In general, it was found that in the year 2012, the practices are converging with IAS 28 in the different countries. We noted almost full convergence with international standards issued by the IASB; Bolivia following the local regulations in force issued by CAUB, in the absence of speech, it is used to IASB standards; for Chile 's foreseen regulatory convergence for the year 2013 and Colombia in 2015. Finally, it is clear that there is still a way to go, so that the countries of the Andean Community, the accounting practices relating to investments in subsidiaries are fully harmonized, converging to internationally accepted accounting standards. 
Tratamento Contábil no Mercosul e na Comunidade Andina: Um Estudo sobre os Investimentos

em Empresas Coligadas e Controladas

João Luis Peruchena Thomaz, Clóvis Antônio Kronbauer, Diego Saldo Alves, Adriana Kurtz Pasini,

Debora Skibinksi Assumpção

Keywords: Measurement and Reporting. Investments in Subsidiaries and Affiliates. Accounting Convergence. Mercosur. Andean Community.

\section{INTRODUÇÃO}

Por volta de 1750 inicia-se o processo de integração econômica na América Latina, cujos precursores foram os venezuelanos Francisco Mirando e Simon Bolívar (SOARES, 1996; KUNZLER, 2001). Mais tarde, em 1915, surge o "Tratado del ABC", acordo político entre Argentina, Brasil e Chile, cujo objetivo era o equilíbrio no Cone Sul. Em 1948 é criada a Comissão Econômica para a América Latina (CEPAL), com a ideia de estimular a criação de um mercado comum Latino-americano. Com o tratado de Montevideo (TM-60), cria-se a Associação Latino Americana de Livre Comércio (ALALC), composta pelos seguintes países: Argentina, Brasil, Chile, México, Uruguai, Paraguai e Peru, e mais tarde Colômbia, Equador, Venezuela e Bolívia aderem ao bloco (SOSA, 2007).

Com o fracasso da ALALC, em agosto de 1980, surge a Associação LatinoAmericana de Integração (ALADI), com objetivos mais modestos. Esse processo facilitou acordos bilaterais entre os países envolvidos (RÊGO, 1995). Argentina e Brasil assinam o programa de integração e cooperação econômica (PICE), mais tarde, em 1988, o Tratado de Integração, Cooperação e Desenvolvimento, visando à formação de uma zona de livre comércio; já em 1990 assinam a Ata de Buenos Aires, dando impulso e acelerando esse processo, já que em dezembro do mesmo ano assinam o Acordo de Complementação Econômica (ACE-14), em que os dois países criam o Grupo Mercado Comum (GMC) (RÊGO, 1995). Então, em 1991 o Uruguai e o Paraguai incorporam-se ao grupo e, em março de 1991 é assinado o Tratado de Assunção, dando início à constituição do Mercosul. Segundo Basso (1995), esse bloco econômico está classificado como terceiro nível de integração econômica, que é livre comércio, união aduaneira e livre circulação de pessoas, serviços, bens e capitais.

Entretanto, o bloco econômico Comunidade Andina não avançou tanto quanto o Mercosul, pois, segundo Basso (1995), o mesmo encontra-se em seu segundo nível de 
Tratamento Contábil no Mercosul e na Comunidade Andina: Um Estudo sobre os Investimentos em Empresas Coligadas e Controladas João Luis Peruchena Thomaz, Clóvis Antônio Kronbauer, Diego Saldo Alves, Adriana Kurtz Pasini, Debora Skibinksi Assumpção

integração econômica, implicando em livre comércio (eliminação ou redução das taxas aduaneira e restrições ao intercâmbio comercial) e união aduaneira (livre comércio e estabelecimento de uma tarifa externa comum). Sua constituição teve início em 1960, com a Declaração de Bogotá, criando o acordo sub-regional andino entre os presidentes dos países da Colômbia, do Chile e da Venezuela (SOSA; FERRETTI, 2007). Em 1969 assinam o Acordo de Cartagena, tomando a denominação de Pacto Andino, com adesão do Equador e do Peru, e a saída, no mesmo ano, do Chile e, em 2006, da Venezuela (SOSA; FERRETTI, 2007). Com o Protocolo de Quito, em 1987, recupera-se o processo de integração entre os países-membros, mas, em 1997, através do Protocolo de Trujillo, o Acordo de Cartagena é modificado, criando a Comunidade Andina (GERMÁNICO, 1998).

Diante deste cenário de integração econômica, é necessário que o processo de geração de informações financeiras esteja integrado, embora características individuais de cada país possam permanecer. Este é um fator que traz implicações importantes nas normas e práticas contábeis nos países destes dois blocos econômicos. No Mercosul e na Comunidade Andina, essa integração ainda não ocorreu. Kronbauer (2006) explica que para a contabilidade esse processo de harmonização é um desafio marcado pela busca de um conjunto mínimo de normas contábeis, que devem ser adotadas pelos países-membros da união econômica e monetária.

Especificamente, a harmonização de práticas contábeis está relacionada aos critérios de avaliação patrimonial, até porque diferentes critérios causam diferença no valor das empresas e acabam interferindo no valor dos resultados apurados. Assim, a adoção de um conjunto harmônico de normas contábeis poderia diminuir a assimetria de informações divulgadas.

Com a convergência aos padrões internacionais de contabilidade, os investimentos em coligadas e controladas sofreram mudanças em seu tratamento contábil, principalmente em sua mensuração para a IAS 28: Método de equivalência patrimonial. Diante disso, o objetivo principal deste estudo é investigar as normas e práticas contábeis adotadas por empresas industriais do MERCOSUL e da Comunidade 
Tratamento Contábil no Mercosul e na Comunidade Andina: Um Estudo sobre os Investimentos em Empresas Coligadas e Controladas João Luis Peruchena Thomaz, Clóvis Antônio Kronbauer, Diego Saldo Alves, Adriana Kurtz Pasini, Debora Skibinksi Assumpção

Andina relativas aos investimentos em coligadas e controladas, avaliando o nível de convergência no tratamento contábil destes elementos patrimoniais.

A escolha deste tema deu-se em função de estudos precedentes terem sido realizados somente no âmbito do Mercosul (POHLMANN, 1995; LISBOA, 2000; AMENÁBAR, 2001). Além disso, a pesquisa possibilita a identificação e a comparação de estudos realizados no ano de 2012, assim como da atual situação do processo de convergência das normas contábeis nestes blocos econômicos.

\section{REFERENCIAL TEÓRICO}

\subsection{Normas contábeis internacionais e o processo de convergência no Mercosul e na Comunidade Andina}

Em uma economia globalizada a contabilidade cumpre o papel de fornecer informação financeira adequada para a tomada de decisão e acessível a mercados internacionais (SOSA, 1999). Diante deste contexto, a globalização da economia é considerada o principal propulsor do processo de harmonização contábil, que tem por finalidade atingir um alto grau de comparabilidade da informação financeira no âmbito internacional, facilitando a comunicação e contribuindo para a redução de diferenças internacionais no financial reporting (NIYAMA, 2010).

Em 1973 surge o Comitê de Normas Internacionais de Contabilidade (IASC), representando mais de 143 entidades profissionais e envolvendo mais de 100 países. Este organismo, reformulado no ano de 2001, passou a ser denominado The International Accounting Standards Board (IASB), e tem por responsabilidade a emissão de normas contábeis de aplicação internacional (MACIEL, 2009).

A convergência aos padrões contábeis internacionais no Mercosul e na Comunidade Andina é diferenciada em cada país que compõe estes blocos econômicos. Na Argentina, a Comissão Nacional de Valores (CNV), a Federação Argentina de Conselhos Profissionais de Ciências Econômicas e o Conselho Profissional de Ciências Econômicas da Cidade Autônoma de Buenos Aires elaboraram 
Tratamento Contábil no Mercosul e na Comunidade Andina: Um Estudo sobre os Investimentos em Empresas Coligadas e Controladas João Luis Peruchena Thomaz, Clóvis Antônio Kronbauer, Diego Saldo Alves, Adriana Kurtz Pasini, Debora Skibinksi Assumpção

conjuntamente um plano de implementação das normas contábeis emitidas pelo IASB. A Resolução Técnica no 26 e 29 da (FACPCE) determinou a obrigatoriedade da adoção pelas entidades que estão sob o controle da CNV, bem como a Resolução Geral no $562 / 2009$ da (CNV), a partir de 01.01.2012. Tais empresas poderiam adotar voluntariamente as normas internacionais a partir de 2011, e de forma obrigatória em 2012.

Na Bolívia, o Colégio de Auditores e Contadores Públicos da Bolívia assinou um convênio de cooperação técnica com o Banco Interamericano de Desenvolvimento, denominado projeto ATN/MT-100078-BO, o qual estabeleceu um plano de convergência das normas bolivianas às normas internacionais. Conforme a Resolução do CTNAC (Consejo Técnico Nacional de Auditoría y Contabilidad) no 001/2012, manteve vigentes as 14 normas de contabilidade geralmente aceitas na Bolívia, emitidas pelo CTNAC da CAUB. No entanto, o artigo $2^{\circ}$ da mesma resolução estabelece que se o país não contar com pronunciamentos técnicos contábeis específicos, deve-se adotar, substancialmente, as Normas Internacionais de Informação Financeira emitidas pelo IASB.

No Brasil, por meio da Resolução CFC no 1.055/05, criou-se o Comitê de Pronunciamentos Contábeis (CPC), com a finalidade de viabilizar a convergência das normas contábeis brasileiras aos padrões internacionais. Em 2006 o Banco Central do Brasil publicou o Comunicado no 14.259, determinando a obrigatoriedade da elaboração das demonstrações contábeis consolidadas com base nas IFRS (Internacional Financial Reporting Standars), a partir de 2010. Com a Deliberação № 457, a Comissão de Valores Mobiliários (CVM) obrigou as companhias abertas a publicarem suas demonstrações contábeis consolidadas integralmente em IFRS, a partir de 2010. Em 2008, com a vigência da Lei ํo 11.638/2007, modificada pela Lei ํo 11.941/2009, oficializou-se a convergência aos padrões contábeis internacionalmente aceitos. A partir do exercício de 2008, todas as empresas poderiam optar pela elaboração das demonstrações contábeis de acordo com o padrão internacional e, em 2010, deveriam adotar obrigatoriamente estas instruções. 
Tratamento Contábil no Mercosul e na Comunidade Andina: Um Estudo sobre os Investimentos em Empresas Coligadas e Controladas João Luis Peruchena Thomaz, Clóvis Antônio Kronbauer, Diego Saldo Alves, Adriana Kurtz Pasini, Debora Skibinksi Assumpção

No Chile, o Conselho Nacional do Colégio de Contadores aprovou, em 23 de setembro de 1997, o Boletim Técnico № 56, que harmoniza os princípios e as normas contábeis chilenos. Em 2008, o Boletim Técnico ํo 79 estabelece as normas internacionais de informação financeira emitidas pelo IASB como normas de informação contábil chilenas, pela sigla (NICCH); contudo, o Boletim Técnico o 82 aprova o marco de aplicação das normas internacionais de contabilidade, sendo de aplicação geral e obrigatória a partir de 01 de janeiro de 2013 e, de forma opcional, anteriormente, a partir de 01 de janeiro de 2009.

$\mathrm{Na}$ Colômbia, a Lei oo 1314 de 2009 estabeleceu o marco normativo de apresentação das informações financeiras, de acordo com as normas internacionais expedidas pelo IASB; regulamentada pelos Decretos no 2706 e 2784, de 27/12/2012 e 28/12/2012, respectivamente, a Superintendência de Sociedades estabeleceu a transição para a aplicação do modelo geral às normas internacionais de contabilidade, sendo o ano de 2014 de transição e 2015 de convergência às IFRS.

No Equador, a Superintendência de Companhias adotou as normas internacionais de informação financeira e determinou sua aplicação por parte das companhias e entidades sujeitas ao seu controle e vigilância, a partir de 2009, sendo que o exercício de 2010 foi de transição e 2011 obrigatório.

No Paraguai, em 1989, o Conselho Diretivo do Colégio de Contadores emitiu uma resolução que estabeleceu a adoção das normas $n^{0} 1$ a 5 , emitidas pelo IASB, sendo que estas seriam aplicadas até que fossem elaboradas e aprovadas novas normas próprias. Já o Conselho Nacional de Valores estabeleceu que as IFRS teriam vigência a partir de 2008, com aplicação obrigatória para todas as sociedades emissoras de títulos e valores mobiliários de oferta pública. Com a Resolução CG o 02/2011 da Comissão Nacional de Valores, que incorporou a Decisão Mercosul/CMC no $31 / 2010$, ficaram as empresas sob o controle da CNV, apresentando de forma obrigatória suas demonstrações contábeis no ano de 2012, tanto trimestrais quanto anuais, de acordo com os pronunciamentos emitidos pelo IASB (International Accounting Standards Board). 
Tratamento Contábil no Mercosul e na Comunidade Andina: Um Estudo sobre os Investimentos

em Empresas Coligadas e Controladas

João Luis Peruchena Thomaz, Clóvis Antônio Kronbauer, Diego Saldo Alves, Adriana Kurtz Pasini,

Debora Skibinksi Assumpção

No Peru, desde 1997, por meio da Lei das Sociedades, estabeleceu-se a obrigatoriedade das demonstrações financeiras serem preparadas e apresentadas em conformidade com as normas legais e os princípios de contabilidade geralmente aceitos, de acordo com as normas internacionais de contabilidade, de aplicação obrigatória a partir de 2011.

No Uruguai, a convergência aos padrões internacionais de contabilidade iniciou na década de 1990. Já em 2004, o governo uruguaio aprovou a aplicação de todas as normas emitidas pelo IASB; e em 2007 orientou para a adoção integral das normas internacionais de informação financeira do IASB.

Na Venezuela, a emissão de normas contábeis está a cargo da Federação de Contadores Públicos da República Boliviana da Venezuela, a qual definiu que as normas internacionais de contabilidade deveriam ser adotadas a partir de 2008, tornando-se obrigatórias em 2011.

Em cada um dos países que compõem o Mercosul e a Comunidade Andina, há um organismo responsável pela emissão e interpretação das normas contábeis. Contudo, isso não significa que estes organismos emitam normas específicas de abrangência interna. Em vários casos como, por exemplo, Paraguai, Uruguai, Venezuela e Equador, são adotadas as normas internacionais de contabilidade do IASB, sem adaptação ou emissão de uma norma correspondente no país.

Com relação ao nível de convergência às normas internacionais de contabilidade nos países que compõem os dois blocos, constatam-se distinções. Na Colômbia há a recomendação expressa para a adoção das normas internacionais de contabilidade do IASB, e em outros países, como Brasil, Paraguai, Uruguai, Venezuela e Equador, a convergência às IFRS também está efetivada, pois organismos internos que emitem normas contábeis seguem as normas do IASB ao produzir as normas locais. Por sua vez, Argentina, Bolívia, Colômbia, Peru e Chile ainda não estavam convergidos às normas internacionais de contabilidade no ano de 2010. Já em 2012, o único país que ainda não se encontrava nessa situação era a Colômbia. 
Tratamento Contábil no Mercosul e na Comunidade Andina: Um Estudo sobre os Investimentos em Empresas Coligadas e Controladas João Luis Peruchena Thomaz, Clóvis Antônio Kronbauer, Diego Saldo Alves, Adriana Kurtz Pasini,

Dessa forma, o processo de convergência às normas internacionais de contabilidade do IASB no Mercosul e na Comunidade Andina, ainda está em curso. Pelo cronograma estabelecido, no ano de 2015 deverá haver completa convergência normativa com o IASB, nos dois blocos econômicos objeto deste estudo.

\subsection{Tratamento contábil dos investimentos em coligadas e controladas no Mercosul e na Comunidade Andina}

No ano da pesquisa, na Bolívia, no Chile e na Colômbia está em vigor uma norma local que regula o tratamento contábil dos Investimentos em coligadas e controladas, conforme o Quadro 1. Esta norma ainda não está convergida às Normas Internacionais de Contabilidade do IASB, estando esta convergência prevista para os anos de 2013 e 2015. Nesse caso, a mensuração deste ativo na Bolívia e no Chile é baseada no método da equivalência patrimonial (valor patrimonial proporcional). $\mathrm{Na}$ Colômbia, único país componente da Comunidade Andina com processo de convergência mais tardia que os demais países componentes deste bloco econômico, tal mensuração é pelo método da equivalência patrimonial (valor patrimonial proporcional).

Nos tratamentos contábeis específicos da Comunidade Andina, como no caso de Bolívia, Chile e Colômbia, são aplicadas as normas locais de informação financeira, conforme o Quadro 1. Nos demais países, as normas que regulam o tratamento dos investimentos em coligadas e controladas estão parametrizadas pela IAS 28 emitida pelo IASB, conforme apresentado no Quadro 1. Uma coligada é uma entidade, incluindo uma entidade sem personalidade jurídica, como uma associação, sobre a qual o investidor possui influência significativa da investida (IAS 28, 2011).

Investimentos em coligadas e controladas são reconhecidos quando o investidor exerce influência significativa, que não é nem uma controlada nem uma joint venture do investidor. Tal influência é o poder de participar das decisões sobre as políticas operacionais e financeiras da investida, sem controlar, individualmente ou conjuntamente, tais políticas (IAS 28, 2011). 
Tratamento Contábil no Mercosul e na Comunidade Andina: Um Estudo sobre os Investimentos em Empresas Coligadas e Controladas João Luis Peruchena Thomaz, Clóvis Antônio Kronbauer, Diego Saldo Alves, Adriana Kurtz Pasini, Debora Skibinksi Assumpção

De acordo com as normas contábeis internacionalmente aceitas, os investimentos em coligadas e controladas devem ser mensurados pelo método da equivalência patrimonial para todo o investimento cuja investidora tenha influência significativa. Por este método, todo o investimento é inicialmente reconhecido pelo custo, e o seu valor contábil será aumentado ou diminuído pelo reconhecimento do investidor nos lucros ou prejuízos do período, gerados pela investida após a aquisição (FERREIRA, 2012).

\begin{tabular}{|c|c|c|c|}
\hline $\begin{array}{l}\text { Investimentos } \\
\text { em Coligadas } \\
\text { e Controladas } \\
\end{array}$ & Definição & Mensuração & Evidenciação \\
\hline \multicolumn{4}{|c|}{ MERCOSUL } \\
\hline Argentina & $\begin{array}{c}\text { NIC } 28 \text { - Inversiones en } \\
\text { Asociadas: corresponde a } \\
\text { IAS } 28\end{array}$ & $\begin{array}{c}\text { NIC } 28 \text { - Inversiones en } \\
\text { Asociadas a IAS } 28\end{array}$ & $\begin{array}{c}\text { NIC } 28 \text { - Inversiones en } \\
\text { Asociadas: corresponde a } \\
\text { IAS } 28\end{array}$ \\
\hline Brasil & $\begin{array}{c}\text { CPC } 18 \text { (R2) - } \\
\text { Investimento em coligada, } \\
\text { em controlada e em } \\
\text { empreendimento controlado } \\
\text { e conjunto: corresponde a } \\
\text { IAS 28 (IASB-BV 2012) }\end{array}$ & $\begin{array}{c}\text { CPC } 18(\mathrm{R} 2)- \\
\text { Investimento em } \\
\text { coligada, em controlada e } \\
\text { em empreendimento } \\
\text { controlado e conjunto }\end{array}$ & $\begin{array}{c}\text { CPC } 18(\mathrm{R} 2)- \\
\text { Investimento em } \\
\text { coligada, em controlada e } \\
\text { em empreendimento } \\
\text { controlado e conjunto: } \\
\text { corresponde a IAS 28 } \\
(\text { IASB-BV 2012) }\end{array}$ \\
\hline Paraguai & $\begin{array}{r}\text { NIC } 28-\ln v \\
\text { Asociadas: co } \\
\text { IAS }\end{array}$ & $\begin{array}{r}\mathrm{NIC} 28-\operatorname{In} \mathrm{V} \\
\text { Asociadas }\end{array}$ & $\begin{array}{c}\text { NIC } 28 \text { - Inversiones en } \\
\text { Asociadas: corresponde a } \\
\text { IAS } 28\end{array}$ \\
\hline Uruguai & $\begin{array}{c}\text { NIC } 28 \text { - Inversiones en } \\
\text { Asociadas: corresponde a } \\
\text { IAS } 28\end{array}$ & $\begin{array}{c}\text { NIC } 28 \text { - Inversiones en } \\
\text { Asociadas a IAS } 28\end{array}$ & $\begin{array}{c}\text { NIC } 28 \text { - Inversiones en } \\
\text { Asociadas: corresponde a } \\
\text { IAS } 28\end{array}$ \\
\hline Venezuela & $\begin{array}{c}\text { NIC } 28 \text { - Inversiones en } \\
\text { Asociadas: corresponde a } \\
\text { IAS } 28\end{array}$ & $\begin{array}{r}\text { NIC } 28-\text { Inve } \\
\text { Asociadas a }\end{array}$ & $\begin{array}{c}\text { NIC } 28 \text { - Inversiones en } \\
\text { Asociadas: corresponde a } \\
\text { IAS } 28\end{array}$ \\
\hline \multicolumn{4}{|c|}{ Comunidade Andina } \\
\hline Bolívia & $\begin{array}{c}\text { Norma de Contabilidad } \\
n^{\circ} \text {-7-Valuacion de } \\
\text { Inversiones Permanentes }\end{array}$ & $\begin{array}{c}\text { Norma de Contabilidad } \\
n^{\circ} 7-\text { Valuacion de } \\
\text { Inversiones Permanentes }\end{array}$ & $\begin{array}{c}\text { Norma de Contabilidad } \\
n^{\circ} 7-\text { Valuación de } \\
\text { Inversiones Permanentes }\end{array}$ \\
\hline Chile & $\begin{array}{c}\text { Boletín Técnico no } 11- \\
\text { Tratamento contable de las } \\
\text { inversiones permanentes } \\
\text { en otras empresas }\end{array}$ & $\begin{array}{c}\text { Boletín Técnico } n^{\circ} \text { 11- } \\
\text { Tratamento contable de las } \\
\text { inversiones permanentes } \\
\text { en otras empresas }\end{array}$ & $\begin{array}{c}\text { Boletín Técnico } n^{\circ} \text { 11- } \\
\text { Tratamento contable de las } \\
\text { inversiones permanentes } \\
\text { en otras empresas }\end{array}$ \\
\hline Colômbia & $\begin{array}{c}\text { Decreto no 2649/93 - } \\
\text { Capitulo II - Normas } \\
\text { Técnicas Especificas- } \\
\text { Seccion I - Normas sobre } \\
\text { los Activos - Art. } 61\end{array}$ & $\begin{array}{c}\text { Decreto } \text { no-2649/93 - }^{-26} \text { Capitulo II - Normas } \\
\text { Técnicas Especificas- } \\
\text { Seccion I - Normas sobre } \\
\text { los Activos - Art. } 61\end{array}$ & $\begin{array}{c}\text { Decreto no 2649/93 - Titulo } \\
\text { Primero - Capitulo III - } \\
\text { Regras Básicas - Art. } 15 \\
\text { Revelación Plena }\end{array}$ \\
\hline
\end{tabular}


Tratamento Contábil no Mercosul e na Comunidade Andina: Um Estudo sobre os Investimentos em Empresas Coligadas e Controladas João Luis Peruchena Thomaz, Clóvis Antônio Kronbauer, Diego Saldo Alves, Adriana Kurtz Pasini, Debora Skibinksi Assumpção

\begin{tabular}{|c|c|c|c|}
\hline Equador & $\begin{array}{c}\text { NIC 28 - Inversiones en } \\
\text { Asociadas: corresponde a } \\
\text { IAS 28 }\end{array}$ & $\begin{array}{c}\text { NIC 28-Inversiones en } \\
\text { Asociadas a IAS 28 }\end{array}$ & $\begin{array}{c}\text { NIC 28 - Inversiones en } \\
\text { Asociadas: corresponde a } \\
\text { IAS } 28\end{array}$ \\
\hline Peru & $\begin{array}{c}\text { NIC 28-Inversiones en } \\
\text { Asociadas: corresponde a } \\
\text { IAS 28 }\end{array}$ & $\begin{array}{c}\text { NIC 28-Inversiones en } \\
\text { Asociadas a IAS 28 }\end{array}$ & $\begin{array}{c}\text { NIC 28 - Inversiones en } \\
\text { Asociadas: corresponde a } \\
\text { IAS 28 }\end{array}$ \\
\hline
\end{tabular}

Quadro 1 - Tratamento contábil dos investimentos em coligadas e controladas nos países do Mercosul e Comunidade Andina

Fonte: Elaborado pelos autores.

As divulgações (evidenciação) exigidas, conforme a IFRS 12 (2011), constituem um padrão de divulgação consolidada com uma gama de disclousure sobre os interesses de uma entidade em empresas controladas, controladas em conjunto, entre outras, com o objetivo de divulgar informações que permitam aos usuários das demonstrações financeiras avaliar: i) a natureza e os riscos associados com os seus interesses em outras entidades; ii) os efeitos dos interesses sobre a sua posição financeira, desempenho financeiro e fluxo de caixa.

\subsection{Estudos antecedentes sobre a harmonização contábil e as normas internacionais de contabilidade}

Dentre os estudos sobre o tema da convergência das normas contábeis aos padrões internacionais podem ser citados o de Cella et al. (2011) nos periódicos internacionais, sobre a educação contábil face a convergência e globalização dos relatórios financeiros Observaram que a educação continuada da classe contábil, a harmonização e convergência internacional de contabilidade, além dos assuntos para pesquisa em contabilidade, devem ser o foco da atenção dos educadores em contabilidade, frente às mudanças impostas pela convergência da contabilidade internacional através da globalização dos relatórios financeiros, que carecem ser desenvolvidos permanentemente.

No que tange às diferenças estruturais e culturais entre as normas internacionais e as divergências no processo de regulamentação adotadas em vários países e órgãos emissores de padrões contábeis, Silva et al. (2004) apontam para uma divisão do mundo em dois campos distintos, ou seja, os seguidores do IASB e os do FASB, 
Tratamento Contábil no Mercosul e na Comunidade Andina: Um Estudo sobre os Investimentos em Empresas Coligadas e Controladas João Luis Peruchena Thomaz, Clóvis Antônio Kronbauer, Diego Saldo Alves, Adriana Kurtz Pasini, Debora Skibinksi Assumpção

embora já houvesse uma tendência à harmonização entre esses organismos. Também apontam para uma existência de resistências regionais apoiadas nos sistemas jurídicos de cada país, tradições, regionalismos e nacionalismos exacerbados, como fatores que retardavam o processo de harmonização contábil.

Os procedimentos contábeis adotados para a mensuração dos ativos, objeto em estudo, foram abordados especificamente no âmbito dos dois blocos econômicos de forma mais genérica. Bloom (2009) examinou o reconhecimento do goodwill concebido internamente e aquele comprado de terceiros. Há um consenso de que o ativo referido, gerado internamente, não deva ser reconhecido como intangível. $O$ autor aponta a necessidade de um tratamento único do goodwill adquirido, já que a informação atribuível a este elemento é útil para as pessoas que efetuam avaliações ou tomam decisões relativas à essa entidade.

Amenábar (2001) analisou o processo de harmonização contábil na Argentina, no Brasil, no Peru e na Venezuela, por meio da identificação das principais semelhanças e diferenças nas normas contábeis utilizadas.

Já Beuren e Brandão (2001) apresentam as formas como está organizada e regulamentada a profissão contábil em cada país-membro do Mercosul, a legislação vigente sobre a elaboração das demonstrações contábeis de divulgação obrigatória, a estrutura e o conteúdo delas, além de explicar as congruências e divergências na estrutura dessas demonstrações, concluindo que ainda é preciso avançar para uma completa harmonização e estrutura da profissão contábil nos países-membros do Mercosul.

Pesquisas relativas a metodologia empregada na mensuração de estoques foram desenvolvidas nos últimos anos, e estão relacionadas com a aplicação nas normas internacionais de contabilidade. Destaque para Murphy (2005) que verificou, em um grupo de empresas, a adoção de normas internacionais de contabilidade que fez com que elas alterassem os métodos contábeis relativos aos estoques. Constatou que as normas internacionais do IASB influenciaram diretamente na escolha de novas metodologias para mensuração desses elementos, embora o nível de harmonização 
Tratamento Contábil no Mercosul e na Comunidade Andina: Um Estudo sobre os Investimentos em Empresas Coligadas e Controladas João Luis Peruchena Thomaz, Clóvis Antônio Kronbauer, Diego Saldo Alves, Adriana Kurtz Pasini, Debora Skibinksi Assumpção

das informações tenha diminuído, visto a falta de divulgação de informações conforme os padrões.

Reis e Stocken (2007) analisaram as consequências da mensuração desses ativos pelo custo histórico e pelo valor justo em um mercado competitivo. Observaram que com a utilização do valor justo, em evidência na IAS 2, os relatórios financeiros revelaram, de maneira completa, a real situação dos estoques e isso proporciona a geração de maiores lucros esperados, diminuição de incertezas, além de gerar maior bem-estar social para a empresa.

Constata-se com base nos estudos precedentes, ainda ocorrem disparidades no tratamento dos ativos. Há oportunidades de pesquisas sobre os procedimentos contábeis relativos a esses elementos e sua harmonização em âmbito mundial. Devido à sua importância, a harmonização contábil proporciona relevância às pesquisas que contribuam para a melhoria nos procedimentos técnicos contábeis relacionados a esses elementos patrimoniais.

\section{CONSIDERAÇÕES METODOLÓGICAS}

O presente estudo é caracterizado como uma pesquisa aplicada e descritiva. Aplicada porque busca contribuir com fins práticos para a geração de conhecimento da temática abordada, com a finalidade de identificar e analisar, a partir dos relatórios contábeis, as assimetrias ou simetrias existentes na avaliação e na evidenciação de elementos patrimoniais (investimento em coligada e em controlada), em empresas do setor industrial dos países integrantes do Mercosul e da Comunidade Andina. É descritiva porque objetiva descrever e analisar as práticas contábeis observadas, procurando avaliar o estágio de harmonização e convergência na mensuração e evidenciação dos ativos que são objeto de estudo nestes países. Quanto à abordagem do problema, a pesquisa pode ser definida como qualitativa, visto que não foi aplicada nenhuma técnica estatística de mensuração e análise do problema. 
Tratamento Contábil no Mercosul e na Comunidade Andina: Um Estudo sobre os Investimentos em Empresas Coligadas e Controladas João Luis Peruchena Thomaz, Clóvis Antônio Kronbauer, Diego Saldo Alves, Adriana Kurtz Pasini,

Com relação aos procedimentos de coleta dos dados, aplicou-se uma pesquisa documental. Foram utilizadas informações contidas nas publicações oficiais das companhias definidas na amostra referentes ao ano de 2012, disponíveis nas páginas eletrônicas dos organismos que regulam o mercado de capitais de cada país.

A população é constituída pelas companhias abertas que negociam suas ações nos mercados de capitais dos países integrantes dos blocos econômicos do Mercosul e da Comunidade Andina. De um total de 2.128 empresas registradas no site da CNV e da CVM, foram identificadas 295 empresas do ramo industrial. A partir da quantidade de empresas industriais destes países, optou-se por selecionar três empresas em cada país, sendo que o critério de escolha foi o maior faturamento anual combinado com maior valor de ativos. A amostra final é constituída por 30 empresas, representando, assim, $10 \%$ da população.

Os dados coletados na pesquisa foram analisados por meio da técnica de análise de conteúdo, em três fases: pré-análise, exploração do material e interpretação (BARDIN, 2009). Inicialmente, foram identificadas e discutidas as normas que regulam o tratamento contábil nos investimentos em coligadas e controladas nos diferentes países. Posteriormente, foram descritos e analisados os métodos de mensuração e evidenciação dos ativos objeto de estudo.

\section{RESULTADOS DO ESTUDO}

\subsection{Avaliação e evidenciação dos investimentos e coligadas e controladas em empresas dos países do Mercosul}

Com relação aos critérios de mensuração adotados pelas empresas do Mercosul, no Quadro 2 apresentam-se os principais procedimentos adotados no ano de 2012. 
Tratamento Contábil no Mercosul e na Comunidade Andina: Um Estudo sobre os Investimentos em Empresas Coligadas e Controladas João Luis Peruchena Thomaz, Clóvis Antônio Kronbauer, Diego Saldo Alves, Adriana Kurtz Pasini,

Debora Skibinksi Assumpção

\begin{tabular}{|c|c|c|c|c|c|}
\hline $\begin{array}{c}\text { Investimentos } \\
\text { em coligadas e } \\
\text { controladas }\end{array}$ & Argentina & Brasil & Paraguai & Uruguai & Venezuela \\
\hline Mensuração & $\begin{array}{c}\text { Método } \\
\text { Equivalência } \\
\text { Patrimonial }\end{array}$ & $\begin{array}{c}\text { Método } \\
\text { Equivalência } \\
\text { Patrimonial }\end{array}$ & $\begin{array}{c}\text { Método } \\
\text { Equivalência } \\
\text { Patrimonial }\end{array}$ & $\begin{array}{c}\text { Método } \\
\text { Equivalência } \\
\text { Patrimonial }\end{array}$ & $\begin{array}{c}\text { Método } \\
\text { Equivalência } \\
\text { Patrimonial }\end{array}$ \\
\hline
\end{tabular}

Quadro 2 - Mensuração dos investimentos em coligadas e controladas em empresas do Mercosul Fonte: Elaborado pelos autores.

Com base nos dados expostos no Quadro 2, observa-se que as empresas de todos os países utilizam como critério de mensuração dos investimentos em coligadas e controladas o método de equivalência patrimonial, o que remete à convergência às Normas Internacionais do IASB (IAS 28). Observou-se, também, harmonização nas práticas contábeis nos países em que as empresas estudadas possuem investimentos.

Na sequência (Quadro 3) apresenta-se a divulgação de informações relativas aos investimentos em coligadas e controladas pelas empresas do Mercosul. São explicitadas as principais políticas adotadas e identificadas nos balanços patrimoniais e nas notas explicativas. 
Tratamento Contábil no Mercosul e na Comunidade Andina: Um Estudo sobre os Investimentos em Empresas Coligadas e Controladas João Luis Peruchena Thomaz, Clóvis Antônio Kronbauer, Diego Saldo Alves, Adriana Kurtz Pasini, Debora Skibinksi Assumpção

\begin{tabular}{|c|c|c|c|c|c|}
\hline $\begin{array}{c}\text { Evidenciação } \\
\text { dos } \\
\text { investimentos } \\
\text { em coligadas } \\
\text { e controladas }\end{array}$ & Argentina & Brasil & Paraguai & Uruguai & Venezuela \\
\hline $\begin{array}{c}\text { Balanço } \\
\text { Patrimonial }\end{array}$ & $\begin{array}{c}\text {-Conta: } \\
\text { Inversiones en } \\
\text { controladas } \\
\text {-Valor: total do } \\
\text { grupo }\end{array}$ & $\begin{array}{l}\text {-Conta: } \\
\text { Investimentos } \\
\text {-Valor: total do } \\
\text { grupo }\end{array}$ & $\begin{array}{c}\text {-Conta: } \\
\text { Inversiones en } \\
\text { Otras Empresas } \\
\text {-Valor: total do } \\
\text { grupo }\end{array}$ & $\begin{array}{l}\text {-Conta: } \\
\text { Inversiones a } \\
\text { largo plazo } \\
\text {-Valor: total do } \\
\text { grupo }\end{array}$ & $\begin{array}{l}\text {-Conta: } \\
\text { Inversiones } \\
\text {-Valor: total do } \\
\text { grupo }\end{array}$ \\
\hline \multirow[b]{3}{*}{$\begin{array}{c}\text { Notas } \\
\text { Explicativas }\end{array}$} & $\begin{array}{l}\text {-Políticas } \\
\text { contábeis e } \\
\text { critério de } \\
\text { avaliação. }\end{array}$ & $\begin{array}{l}\text {-Políticas } \\
\text { contábeis e } \\
\text { critério de } \\
\text { avaliação. }\end{array}$ & $\begin{array}{l}\text {-Políticas } \\
\text { contábeis e } \\
\text { critério de } \\
\text { avaliação. }\end{array}$ & $\begin{array}{l}\text {-Políticas } \\
\text { contábeis e } \\
\text { critério de } \\
\text { avaliação. }\end{array}$ & $\begin{array}{l}\text {-Políticas } \\
\text { contábeis e } \\
\text { critério de } \\
\text { avaliação. }\end{array}$ \\
\hline & $\begin{array}{l}\text {-Detalhamento } \\
\text { das contas dos } \\
\text { investimentos } \\
\end{array}$ & $\begin{array}{l}\text {-Detalhamento } \\
\text { das contas dos } \\
\text { investimentos }\end{array}$ & $\begin{array}{l}\text {-Detalhamento } \\
\text { das contas dos } \\
\text { investimentos }\end{array}$ & $\begin{array}{l}\text {-Detalhamento } \\
\text { das contas dos } \\
\text { investimentos }\end{array}$ & $\begin{array}{l}\text {-Detalhamento } \\
\text { das contas dos } \\
\text { investimentos }\end{array}$ \\
\hline & $\begin{array}{l}\text {-Composição } \\
\text { do saldo dos } \\
\text { investimentos. } \\
\text {-Movimentação } \\
\text { do saldo em } \\
\text { quantidade de } \\
\text { ações. } \\
\text {-Resultado } \\
\text { sobre o lucro } \\
\text { líquido do } \\
\text { exercício, } \\
\text { individualizado. }\end{array}$ & $\begin{array}{l}\text {-Composição do } \\
\text { saldo dos } \\
\text { investimentos. } \\
\text {-Movimentação } \\
\text { do saldo em } \\
\text { quantidade de } \\
\text { ações } \\
\text { ordinárias/quotas } \\
\text { possuídas. } \\
\text {-Resultado sobre } \\
\text { o lucro líquido do } \\
\text { exercício, } \\
\text { individualizado. }\end{array}$ & $\begin{array}{l}\text {-Composição do } \\
\text { saldo dos } \\
\text { investimentos. } \\
\text {-Movimentação } \\
\text { do saldo em } \\
\text { quantidade de } \\
\text { ações } \\
\text { ordinárias/quotas } \\
\text { possuídas. } \\
\text {-Resultado sobre } \\
\text { o lucro líquido do } \\
\text { exercício, } \\
\text { individualizado. }\end{array}$ & $\begin{array}{l}\text {-Composição do } \\
\text { saldo dos } \\
\text { investimentos. } \\
\text {-Movimentação } \\
\text { do saldo em } \\
\text { quantidade de } \\
\text { ações } \\
\text { ordinárias/quotas } \\
\text { possuídas. } \\
\text {-Resultado sobre } \\
\text { o lucro líquido do } \\
\text { exercício, } \\
\text { individualizado. }\end{array}$ & $\begin{array}{l}\text {-Composição do } \\
\text { saldo dos } \\
\text { investimentos. } \\
\text {-Movimentação } \\
\text { do saldo em } \\
\text { quantidade de } \\
\text { ações } \\
\text { ordinárias/quotas } \\
\text { possuídas. } \\
\text {-Resultado sobre } \\
\text { o lucro líquido do } \\
\text { exercício, } \\
\text { individualizado. }\end{array}$ \\
\hline
\end{tabular}

Quadro 3 - Evidenciação dos investimentos em coligadas e controladas em empresas do Mercosul Fonte: Elaborado pelos autores.

Com base nos dados do Quadro 3, observa-se que nas empresas dos países do Mercosul os investimentos em coligadas e controladas são apresentados no Balanço Patrimonial em conta individual com o valor global agrupado.

As diferenças existentes na apresentação desse ativo no Balanço Patrimonial decorrem da nomenclatura, visto que: as empresas argentinas adotam Investimentos em Controladas (Inversiones en Controladas), e as do Uruguai, Investimentos a Longo Prazo (Inversiones a Largo Plazo); no Brasil, as empresas utilizam a conta denominada de Investimentos; no Paraguai adotam Investimentos em Outras Empresas (Inversiones en Otras Empresas); e na Venezuela as empresas estudadas adotam a conta 
Tratamento Contábil no Mercosul e na Comunidade Andina: Um Estudo sobre os Investimentos em Empresas Coligadas e Controladas João Luis Peruchena Thomaz, Clóvis Antônio Kronbauer, Diego Saldo Alves, Adriana Kurtz Pasini, Debora Skibinksi Assumpção

Investimentos (Inversiones). Entende-se que estas diferenças de nomenclatura podem ser decorrentes das diferenças de linguagem, mesmo que na maioria dos países o idioma seja o mesmo.

Com relação às informações reveladas nas notas explicativas, observa-se que todas as empresas pesquisadas apresentam uma nota comum, informando as políticas contábeis adotadas e o método de mensuração empregado para a determinação dos valores do ativo.

Também há uma uniformidade com relação à nota explicativa que detalha, item por item, a composição dos saldos dos investimentos, sua movimentação e o resultado sobre o lucro líquido do exercício individualizado.

Assim, nas análises inerentes ao Quadro 3, verifica-se a convergência nas empresas com a Norma Internacional de Contabilidade - IAS 28, relativa aos investimentos em coligadas e controladas.

\subsection{Avaliação e evidenciação dos investimentos em coligadas e controladas em empresas dos países da Comunidade Andina}

O critério de mensuração dos investimentos em coligadas e controladas nas empresas da Comunidade Andina é apresentado no Quadro 4.

\begin{tabular}{|c|c|c|c|c|c|}
\hline $\begin{array}{c}\text { Investimentos } \\
\text { em Coligadas } \\
\text { e Controladas }\end{array}$ & Bolívia & Chile & Colômbia & Equador & Peru \\
\hline Mensuração & $\begin{array}{c}\text {-Método } \\
\text { Equivalência } \\
\text { Patrimonial }\end{array}$ & $\begin{array}{c}\text {-Método } \\
\text { Equivalência } \\
\text { Patrimonial }\end{array}$ & $\begin{array}{c}\text {-Ausência de } \\
\text { notas } \\
\text { explicativas }\end{array}$ & $\begin{array}{c}\text {-Método } \\
\text { Equivalência } \\
\text { Patrimonial }\end{array}$ & $\begin{array}{c}\text {-Método } \\
\text { Equivalência } \\
\text { Patrimonial }\end{array}$ \\
\hline
\end{tabular}

Quadro 4 - Mensuração dos investimentos em coligadas e controladas em empresas da Comunidade Andina

Fonte: Elaborado pelos autores.

Os dados expostos no Quadro 4 revelam que nas empresas de quatro países (Bolívia, Chile, Equador e Peru) o critério de mensuração dos investimentos em coligadas e controladas é, predominantemente, o método de equivalência patrimonial. A exceção são as empresas colombianas, nas quais não se identificou o referido critério 
Tratamento Contábil no Mercosul e na Comunidade Andina: Um Estudo sobre os Investimentos em Empresas Coligadas e Controladas João Luis Peruchena Thomaz, Clóvis Antônio Kronbauer, Diego Saldo Alves, Adriana Kurtz Pasini, Debora Skibinksi Assumpção

pela falta de publicação de notas explicativas inerentes às demonstrações contábeis publicadas na página web da Superintendência Financeira da Colômbia.

Com relação aos critérios de mensuração dos investimentos em coligadas e controladas adotados pelas empresas da Comunidade Andina, verifica-se convergência à Norma Internacional do IASB (IAS 28) em quatro países, visto que todos os critérios divulgados pelas empresas pesquisadas estão previstos na referida norma contábil.

No Quadro 5 constam os critérios de evidenciação no Balanço Patrimonial e em notas explicativas, dos investimentos em coligadas e controladas de empresas industriais da Comunidade Andina.

\begin{tabular}{|c|c|c|c|c|c|}
\hline $\begin{array}{l}\text { Evidenciação } \\
\text { dos } \\
\text { investimentos } \\
\text { em Coligadas } \\
\text { e Controladas }\end{array}$ & Bolívia & Chile & Colômbia & Equador & Peru \\
\hline $\begin{array}{c}\text { Balanço } \\
\text { Patrimonial }\end{array}$ & $\begin{array}{c}\text {-Conta: } \\
\text { Inversiones en } \\
\text { Sociedades } \\
\text {-Valor: total do } \\
\text { grupo }\end{array}$ & $\begin{array}{c}\text {-Conta: } \\
\text { Inversiones en } \\
\text { Asociadas } \\
\text { Valor: total do } \\
\text { grupo } \\
\end{array}$ & $\begin{array}{c}\text {-Conta: } \\
\text { Inversiones a } \\
\text { Largo Plazo } \\
\text {-Valor: total do } \\
\text { grupo }\end{array}$ & $\begin{array}{c}\text {-Conta: } \\
\text { Inversiones } \\
\text { Permanentes } \\
\text {-Valor: total do } \\
\text { grupo }\end{array}$ & $\begin{array}{c}\text {-Conta: } \\
\text { Inversiones en } \\
\text { Asociadas } \\
\text {-Valor: total do } \\
\text { grupo }\end{array}$ \\
\hline & $\begin{array}{l}\text {-Políticas } \\
\text { contábeis e } \\
\text { critério de } \\
\text { avaliação }\end{array}$ & $\begin{array}{l}\text {-Políticas } \\
\text { contábeis e } \\
\text { critério de } \\
\text { avaliação }\end{array}$ & $\begin{array}{l}\text {-Não possui } \\
\text { dados para } \\
\text { análise }\end{array}$ & $\begin{array}{l}\text {-Políticas } \\
\text { contábeis e } \\
\text { critério de } \\
\text { avaliação }\end{array}$ & $\begin{array}{l}\text {-Políticas } \\
\text { contábeis e } \\
\text { critério de } \\
\text { avaliação }\end{array}$ \\
\hline & $\begin{array}{l}\text {-Detalhamento } \\
\text { das contas dos } \\
\text { investimentos }\end{array}$ & $\begin{array}{l}\text {-Detalhamento } \\
\text { das contas dos } \\
\text { investimentos }\end{array}$ & $\begin{array}{l}\text {-Não possui } \\
\text { dados para } \\
\text { análise }\end{array}$ & $\begin{array}{l}\text {-Detalhamento } \\
\text { das contas dos } \\
\text { investimentos }\end{array}$ & $\begin{array}{l}\text {-Detalhamento } \\
\text { das contas do } \\
\text { imobilizado }\end{array}$ \\
\hline $\begin{array}{c}\text { Notas } \\
\text { Explicativas }\end{array}$ & $\begin{array}{l}\text {-Composição do } \\
\text { saldo dos } \\
\text { investimentos. }\end{array}$ & \begin{tabular}{|l|}
-Composição do \\
saldo dos \\
investimentos. \\
-Movimentação \\
do saldo em \\
quantidade de \\
ações \\
ordinárias/quotas \\
possuídas. \\
-Resultado sobre \\
o lucro líquido do \\
exercício, \\
individualizado.
\end{tabular} & $\begin{array}{l}\text {-Não possui } \\
\text { dados para } \\
\text { análise }\end{array}$ & $\begin{array}{l}\text {-Composição } \\
\text { do saldo dos } \\
\text { investimentos. }\end{array}$ & $\begin{array}{l}\text {-Composição do } \\
\text { saldo dos } \\
\text { investimentos. } \\
\text {-Movimentação } \\
\text { do saldo dos } \\
\text { investimentos } \\
\text { nas associadas. }\end{array}$ \\
\hline
\end{tabular}

Quadro 5 - Evidenciação dos investimentos em coligadas e controladas em empresas da Comunidade Andina

Fonte: Elaborado pelos autores. 
Tratamento Contábil no Mercosul e na Comunidade Andina: Um Estudo sobre os Investimentos em Empresas Coligadas e Controladas João Luis Peruchena Thomaz, Clóvis Antônio Kronbauer, Diego Saldo Alves, Adriana Kurtz Pasini,

Examinando os dados do Quadro 5, observa-se que nas empresas dos países da Comunidade Andina os investimentos em coligadas e controladas é apresentado no Balanço Patrimonial em conta individual, com seu valor global. Em empresas de dois países (Chile e Peru), os ativos são apresentados no Balanço Patrimonial, na conta Investimentos em Associadas (Inversiones en Asociadas); enquanto que na Bolívia as empresas utilizam a conta Investimentos em Sociedades (Inversiones en Sociedades). Já em empresas equatorianas é adotada a designação Investimentos Permanentes (Inversiones Permanentes); e nas empresas colombianas é utilizada a nomenclatura Investimentos a Longo Prazo (Inversiones a Largo Plazo). Observa-se, assim, que há somente divergência na nomenclatura, a qual pode ser decorrente de características de linguagem, mesmo que o idioma seja o espanhol em todos os países.

Com relação às informações reveladas nas notas explicativas, observa-se nas empresas industriais de quatro países (Bolívia, Chile, Equador e Peru), uma nota explicativa comum, informando as políticas adotadas e o método de avaliação na determinação do valor dos investimentos em coligadas e controladas. Nestes quatro países há uma uniformidade na nota explicativa que detalha, item por item, a composição do valor global líquido destes ativos apresentados no Balanço Patrimonial.

É evidenciado nas notas explicativas em empresas chilenas, além dessa composição, as movimentações, saldo e quantidade de ações, bem como o resultado sobre o lucro líquido do exercício, individualizado. Já nas empresas peruanas, há uma nota com a movimentação do saldo dos investimentos. Destaca-se, com relação à evidenciação dos investimentos em coligadas e controladas, a aderência às Normas Internacionais do IASB (IAS 28), com exceção das empresas colombianas, cujas notas explicativas não foram divulgadas no sítio oficial do mercado de capitais do país.

\subsection{Convergência à norma do IASB dos investimentos em coligadas e controladas em empresas do Mercosul e da Comunidade Andina}

Para possibilitar uma análise comparativa entre convergência normativa e convergência nas práticas contábeis relativas aos investimentos em coligadas e 
Tratamento Contábil no Mercosul e na Comunidade Andina: Um Estudo sobre os Investimentos em Empresas Coligadas e Controladas João Luis Peruchena Thomaz, Clóvis Antônio Kronbauer, Diego Saldo Alves, Adriana Kurtz Pasini,

Debora Skibinksi Assumpção

controladas nos dois blocos econômicos em estudo, apresenta-se a Figura 1 e a Figura 2.

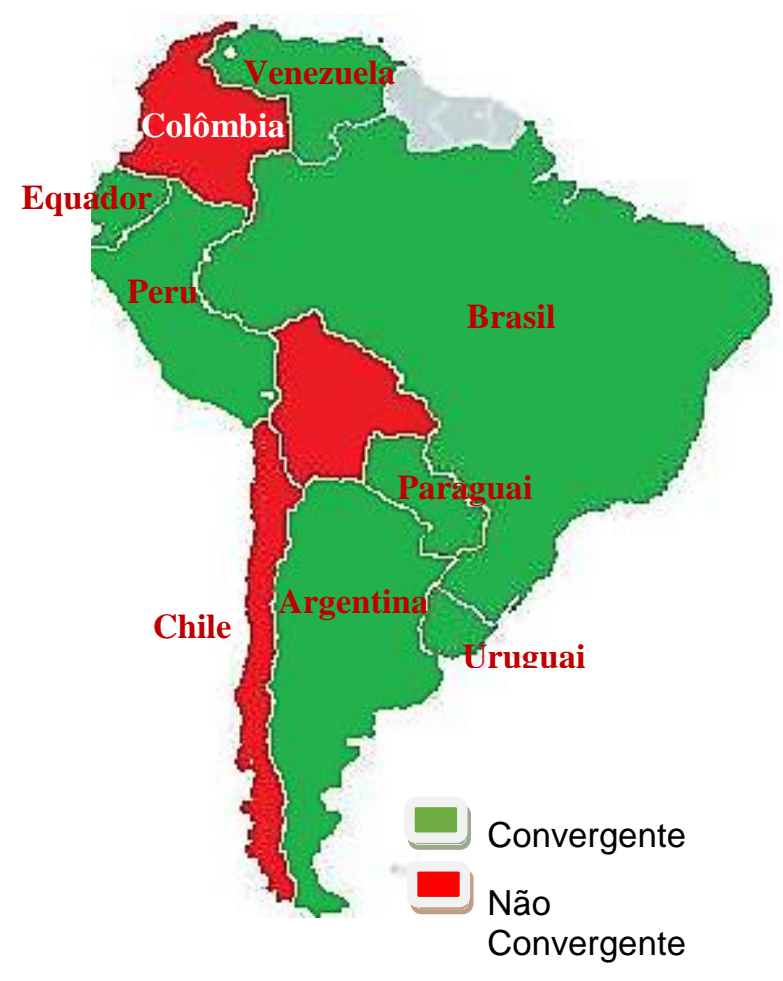

Figura 1 - Convergência das normas estudadas com as normas internacionais de contabilidade em 2012.

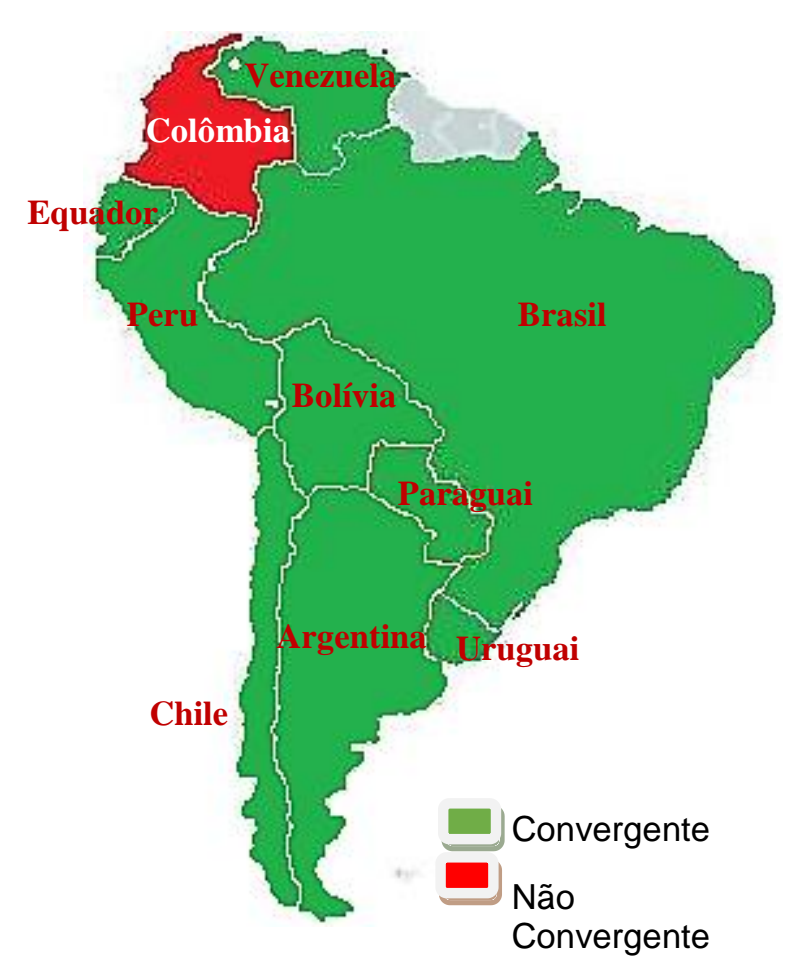

Figura 2 - Convergência das práticas estudadas com as normas internacionais de contabilidade em 2012.

Com referência à convergência aos padrões internacionais, constatam-se aspectos relevantes em relação às empresas dos países do MERCOSUL, na medida que em todas há convergência normativa ao padrão IASB e também é possível identificá-la nas práticas contábeis observadas. Da mesma forma, ocorrem situações peculiares relacionadas com as empresas da Comunidade Andina com relação à convergência.

No Chile não há convergência normativa ao padrão IASB, mas é possível identificá-la nas práticas contábeis observadas nas empresas pesquisadas referente 
Tratamento Contábil no Mercosul e na Comunidade Andina: Um Estudo sobre os Investimentos em Empresas Coligadas e Controladas João Luis Peruchena Thomaz, Clóvis Antônio Kronbauer, Diego Saldo Alves, Adriana Kurtz Pasini,

aos investimentos em coligadas e controladas. No Peru e no Equador há convergência normativa ao padrão IASB e também é possível identificar, nas práticas contábeis observadas nas empresas pesquisadas, a mensuração e evidenciação dos investimentos em coligadas e controladas. Na Colômbia não há convergência normativa ao padrão IASB, nem mesmo nas práticas contábeis das empresas pesquisadas quanto à mensuração e evidenciação dos ativos objeto de estudo.

As constatações advindas do estudo revelam que o processo de convergência à norma internacional de contabilidade (IAS 28), nos países da Comunidade Andina, deve estar concluído até o final de 2015. Para que isso se confirme, o calendário previsto para a convergência, principalmente na Colômbia, deve ter sua conclusão efetivada nas datas estabelecidas. Observa-se que a convergência das normas contábeis aos padrões do IASB é algo iminente nos países desses blocos econômicos, o que pode facilitar o processo de harmonização contábil nesta região.

\section{CONCLUSÃO}

Por meio deste estudo buscou-se analisar o nível de convergência às normas do IASB de práticas contábeis relacionadas aos investimentos em coligadas e controladas, por empresas industriais sediadas nos países do Mercosul e da Comunidade Andina, analisando aspectos relacionados com a mensuração e evidenciação desses ativos.

A partir dos dados coletados, constatou-se que nos países do Mercosul as práticas contábeis estudadas relativas à mensuração e evidenciação dos investimentos em coligadas e controladas estão convergentes com o que requer a IAS 28. $\mathrm{Na}$ Comunidade Andina as empresas de quatro países (Bolívia, Chile, Equador e Peru) apresentaram as práticas contábeis dos investimentos em coligadas e controladas convergentes com o que preconiza a norma do IASB.

A Colômbia é o único país onde as práticas não são convergentes, pois as informações em notas explicativas não estão disponíveis aos usuários. Embora as empresas possam ter publicado seus balanços patrimoniais e demonstrações de 
Tratamento Contábil no Mercosul e na Comunidade Andina: Um Estudo sobre os Investimentos em Empresas Coligadas e Controladas João Luis Peruchena Thomaz, Clóvis Antônio Kronbauer, Diego Saldo Alves, Adriana Kurtz Pasini, Debora Skibinksi Assumpção

resultados, a falta de informações em notas explicativas revela uma grande limitação, remetendo a não convergência com os padrões internacionais. Desse modo, pode-se afirmar que nas empresas da Comunidade Andina e do Mercosul ocorrem práticas contábeis relacionadas ao ativo objeto de estudo, com adequado nível de convergência ao padrão internacional.

Conclui-se a partir do estudo, que no caso das empresas colombianas não foi possível identificar estes tipos de investimentos pela falta da publicação das notas explicativas junto à Superintendência Financeira de Colômbia (SIMEV). Esta constatação está coerente com o que já referiam Silva, Madeira e Assis (2004), visto que eles apontam para a existência de resistências regionais apoiadas nos sistemas jurídicos de cada país, tradições, regionalismos e nacionalismos exacerbados, como fatores que retardam o processo de harmonização contábil.

Isso leva a que se considere que a prática contábil é influenciada pelas características próprias de cada país e que a harmonização não significa a adoção de um padrão único e comum, mas sim harmonizado. Além disso, a adoção de um conjunto de normas comuns, como são as normas internacionais de Contabilidade do IASB, pode não garantir, ao menos de imediato, a adoção de práticas contábeis convergentes e harmonizadas.

Adicionalmente, entende-se como relevantes as contribuições de Cella, Rodrigues e Niyama (2011), que entendem que o foco da atenção dos educadores em contabilidade, para fazer frente às mudanças impostas pela convergência da contabilidade internacional e pela globalização dos relatórios financeiros, deve estar na permanente educação continuada.

Assim, a educação contínua e as pesquisas aplicadas relacionadas ao tema podem contribuir para superar as resistências regionais, tradições, regionalismos e nacionalismos exacerbados, apontados como fatores que retardam o processo de harmonização contábil, e para que se possa alcançar, ao menos em médio prazo, a convergência contábil em níveis mais aceitáveis. 
Tratamento Contábil no Mercosul e na Comunidade Andina: Um Estudo sobre os Investimentos em Empresas Coligadas e Controladas João Luis Peruchena Thomaz, Clóvis Antônio Kronbauer, Diego Saldo Alves, Adriana Kurtz Pasini, Debora Skibinksi Assumpção

Diante deste cenário de integração econômica regional, é importante estimular pesquisas com o objetivo de verificar o processo de harmonização nos países do Mercosul e Comunidade Andina, pois este fator contribui para a geração de informações integradas e harmonizadas, facilitando o acesso à informações uniformes pelos usuários.

Assim, considerando os dados obtidos e a significância do tema abordado, recomenda-se analisar os demais elementos patrimoniais, possíveis divergências estruturais e de conteúdo das demonstrações contábeis de divulgação obrigatória e impactos financeiros na aplicação das normas internacionais do IASB nesses blocos econômicos.

\section{REFERÊNCIAS}

AMENÁBAR, A. M. H. (2001). Harmonização contábil em cinco países da América do Sul. 2001. 415f. (Dissertação de Mestrado). Programa de Pós-Graduação em Controladoria e Contabilidade. Universidade de São Paulo, São Paulo, SP.

BARDIN, L. (2009). Análise de conteúdo. Lisboa: Edições 70, 5.

BASSO, M. Integração econômica e institucionalização: as experiências do Mercosul e da União Europeia. Disponível em: http://www.cjf.gov.br/revista/numero4/artigo9.htm, acesso em 20/novembro/2010.

BEUREN, Ilse Maria; BRANDÃO, Juliana Favero. (2001). Demonstrações contábeis no MERCOSUL: estrutura, análise e harmonização. São Paulo: Atlas.

BLOOM, Martin. (2009). Accounting for goodwill. ABACUS-A. Journal of Accounting, Finance and Business Studies, v. 45, n. 3, p. 379-389.

BOLIVIA. Conselho Técnico Nacional de Auditoria e Contabilidade - CAUB. Resolução técnica CTNAC no 001/2012. Vigência de normas de contabilidade geralmente aceitas na Bolívia. Disponível em: http://www.auditorescontadoresbolivia.org/resoluciones/ctnac0012012.pdf, acesso em 10/06/2013.

.Conselho Técnico Nacional de Auditoria e Contabilidade - CAUB. Resolução técnica CTNAC no 002/2012. Vigência de normas de auditoria geralmente aceitas na 
Tratamento Contábil no Mercosul e na Comunidade Andina: Um Estudo sobre os Investimentos em Empresas Coligadas e Controladas João Luis Peruchena Thomaz, Clóvis Antônio Kronbauer, Diego Saldo Alves, Adriana Kurtz Pasini, Debora Skibinksi Assumpção

Bolívia.

Disponível

em: http://www.auditorescontadoresbolivia.org/resoluciones/ctnac0022012.pdf. Acesso em 10/junho/2013.

CELLA, Gilson; RODRIGUES, Jomar Miranda; NIYAMA, Jorge Katsumi. (2011). Contabilidade Internacional - análise dos periódicos internacionais sobre pesquisas em educação contábil face à convergência e globalização. RCC - Revista Contemporânea de Contabilidade. UFSC, Florianópolis, v. 8, n. 15, p. 177-198.

COLÉGIO DE CONTADORES DO CHILE A.G. Boletim técnico no 79 versão 2010. Normas de informação contábil do Chile - NICCH. Disponível em: http://www.chilecont.cl/?p=1173. Acesso em: 10/junho/2013.

. Boletim técnico $n^{\circ}$ 82. Convergência dos princípios contábeis geralmente aceitos no Chile às Normas internacionais de informação financeira. Disponível em: http://www.chilecont.cl/?p=1173. Acesso em: 10/junho/2013.

COLOMBIA. DECRETO № 2784 de 28 de dezembro de 2012. Regulamenta o marco técnico para apresentação das normas internacionais de informação financeira. Disponível

em http://www.minhacienda.gov.co/portal/page/portal/HomeMinhacienda/regulacionfinancie ra/Decretos/2012/DECRETO\%202784\%20DE\%202012.pdf. Acesso em 10/junho/2013.

COMITÉ DE PRONUNCIAMENTOS CONTÁBEIS. Pronunciamento Técnico CPC 18 (R2): investimento em coligada, controlada e em empreendimento controlado em conjunto. Brasília, DF, 07 de dezembro de 2012. Disponível em http://www.cpc.org.br/pdf/CPC_18.pdf. Acesso em 10/junho/2013.

COMISSÃO NACIONAL DE VALORES DA ARGENTINA. Resolução geral $n^{\circ} 562$ de 29.12.2009 adoção das normas internacionais de informação financeira. Disponível em https://aif.cnv.gov.ar/LeyesyReg/marco_regulatorio3.asp?Lang=0\&item=4. Acesso em 10/junho/2013.

FEDERAÇÃO ARGENTINA DE CONSELHOS PROFISSIONAIS DE CIÊNCIAS ECONÔMICAS. Resolução Técnica no 26 de 20 de março de 2009. Normas contábeis profissionais: adoção das normas internacionais do IASB. Disponível em: http://www.facpce.org.ar:8080/infopro/categorias.php?categoria=3. Acesso em: 10/junho/2013.

. Resolução Técnica no 29 de 19 de março de 2010. Modificação da resolução técnica no 26 normas contábeis profissionais: adoção das normas internacionais do IASB. Disponível em http://www.facpce.org.ar:8080/infopro/categorias.php?categoria=3. Acesso em 10/junho/2013. 
Tratamento Contábil no Mercosul e na Comunidade Andina: Um Estudo sobre os Investimentos em Empresas Coligadas e Controladas João Luis Peruchena Thomaz, Clóvis Antônio Kronbauer, Diego Saldo Alves, Adriana Kurtz Pasini,

FERREIRA, Ricardo J. (2012). Contabilidade avançada: inclui a nova estrutura conceitual comentada - CPC 00. (5. ed.). Rio de Janeiro: Ed. Ferreira.

GERMÁNICO, Salgado P. El Grupo Andino de hoy: eslabón hacia la integración de sudamerica. Quito: Universidad Andina Simón Bolivar del Ecuador, 1998. Disponível em: http://www.uasb.edu.ec/index_publicacion.php?cd=197. Acesso em 15/janeiro/2011.

IFRS. IAS 28 - Investiments in Associates (2011). Disponível em http://www.ifrs.org/DPOC/ifrss/Pages/IAS-28.aspx. Acesso em 10/junho/2013.

IFRS 12 - Disclosure of Interests in other Entities (2011). Disponível em http://www.ifrs.org/IFRSs/Documents/IFRS12.pdf. Acesso em 10/junho/2013.

KRONBAUER, C. A. (2006). Contabilización y divulgación de información relativa al impuesto sobre benefícios: una comparación entre lãs normas españolas y brasileñas. Suficiência investigadora (Trabajo de Investigación). Sevilla, ES.

KUNZLER, J. P. (2001). Mercosul e o comércio exterior. (2. ed.). São Paulo: Aduaneiras.

LISBOA, N. P. Harmonização de normas e práticas contábeis no Mercosul. (2000). 121f. (Tese de Doutorado). Programa de Pós-Graduação em Controladoria e Contabilidade. Universidade de São Paulo, São Paulo, SP.

MACIEL, R. R. (2009). Como implantar as normas internacionais de contabilidade: IFRS. Curitiba: Juruá.

MERCOSUR, Secretaria del. Normativa (2012). Disponível em http://www.mercosur.int/innovaportal/v/4392/1/secretaria/2012. Acesso em 08/agosto/2012.

.MERCOSUL/CMC/DEC. № 31/10. Regulamentação mínima do mercado de valores sobre a elaboração e divulgação das demonstrações financeiras. Disponível em http://www.sice.oas.org/trade/mrcsrs/decisions/DEC3110_p.pdf. Acesso em 10/junho/2013.

MURPHY, A.B. (2005). The influence of international accounting standards on companies choice of accounting methods. Journal of Accounting and Finance. v. 13, n. 2, p. 101-114.

NIYAMA, J. K. (2010). Contabilidade internacional. São Paulo: Atlas. 
Tratamento Contábil no Mercosul e na Comunidade Andina: Um Estudo sobre os Investimentos em Empresas Coligadas e Controladas João Luis Peruchena Thomaz, Clóvis Antônio Kronbauer, Diego Saldo Alves, Adriana Kurtz Pasini, Debora Skibinksi Assumpção

POHLMANN, M. C. (1995). Harmonização contábil no Mercosul: a profissão e o processo de emissão de normas: uma contribuição. Caderno de estudos, São Paulo.

RÊGO, Elba Cristina Lima. (1995). Processo de integração no Mercosul. Revista do BNDES, Rio de Janeiro, v. 2, n. 3, p. 167-196.

REIS, R.R.; STOCKEN, P.C. (2007). Strategic consequences of historical cost and fair value measurements. Contemporary Accounting Research. v. 24, n. 2, p. 557-584.

SILVA, Cátia B. Amaral da; MADEIRA, Geová José; ASSIS, José L. Ferreira de. (2004). Harmonização de Normas contábeis: um estudo sobre as divergências entre normas contábeis internacionais e seus reflexos na contabilidade brasileira. RCC - Revista Contemporânea de Contabilidade. UFSC, Florianópolis, ano 01, v. 1, n. 1, p. 115-139.

SOARES, Maria Susana Arrosa. Mercosul e globalização. (1996). Trabalho apresentado no curso da $3^{a}$ reunião especial do SBPC, Florianópolis.

SOSA, A. J. Origens, evolução e perspectivas do MERCOSUL. Buenos Aires, (1999). Disponível em http://www.amersur.org.ar/Integ/OEPMercosur.htm. Acesso em 15/janeiro/2011.

. El MERCOSUR político: orígenes, evolución y perspectivas. (2008). Buenos Aires, março. Disponível em http://www.amersur.org.ar/lnteg/OEPMercosur.htm. Acesso em 15/janeiro/2011.

SOSA, A. J.; FERRETTI, M. M. América do Sul: um breve relato sobre seu processo de integração. (2007). Buenos Aires, abril. Disponível em http://www.amersur.org.ar/lnteg/OEPMercosur.htm. Acesso em 15/janeiro/2011.

SUPERINTENDENCIA VALORES Y SEGUROS DE CHILE. Oficio circular $n^{\circ} 427$ de 28/12/2007. Disponível em http://www.svs.cl/normativa/ofc_427_2007.pdf. Acesso em 10/junho/2013.

Data de Submissão: 01/09/2014

Data de Aceite: 31/03/2015 